\title{
La literatura brasileña de autoría negra y sus posicionamientos frente a las operaciones blancocéntricas del canon hegemónico ${ }^{1}$
}

\author{
Lucía Tennina \\ Profesora de Literatura Brasileña de la Facultad de Filosofía y Letras \\ Universidad de Buenos Aires \\ https://orcid.ora/0000-0002-5652-6234 \\ luciatennina@gmail.com
}

\section{Resumen}

En este artículo, en primer lugar, se presenta una lectura del perfil que define a la historia de la literatura brasileña, dando cuenta de su blancocentrismo, con pocas excepciones. También, se lleva a cabo un análisis de las bases históricas y conceptuales que fueron forjando un circuito y una escena literarios de autoría negra. Al mismo tiempo, se analizan las operaciones sobre el archivo de la esclavitud que realizan los escritores de autoría negra en diálogo con el canon hegemónico. El corpus de poemas que componen este artículo se concentra en autores del siglo XX: Carolina Maria de Jesus, Edimilson de Almeida Pereira, Eliane Marques, Oswaldo de Camargo, Cuti, Conceição Evaristo, Carlos Assumpção, Mel Duarte. El artículo parte de una concepción ampliada de literatura, por lo que, junto con la literatura de autoría negra, se hace mención también a prácticas culturales no literarias (como la fotografía y las artes plásticas).

Palabras clave: autoría negra; literatura brasileña; blancocentrismo; esclavitud; canon.

\section{Brazilian literature of black authorship and its positions with white- centric operations of the hegemonic canon}

\section{Hbstract}

In this article, first of all, a reading of the profile that defines the history of Brazilian literature is presented, accounting for its white-centeredness, with few exceptions. Also, is carried out an analysis of the historical and conceptual bases that were forging a circuit and a literary scene of black authorship. At the same time, the operations on the archive of slavery carried out by writers of black authorship in dialogue with the hegemonic canon are analyzed. The corpus of poems that make up this article focuses on authors of the 20th century: Carolina Maria de Jesus, Edimilson de Almeida Pereira, Eliane Marques, Oswaldo de Camargo, Cuti, Conceição Evaristo, Carlos Assumpção, Mel Duarte. The article starts from an expanded conception of literature, so

1 Procedencia del artículo: Este artículo es resultados de interés académico personal. 
that along with black authorship literature mention will also be made of non-literary cultural practices (such as photography and plastic arts).

Keywords: black authorship; Brazilian literature; white-centeredness; slavery; canon.

Recibido: 12 de agosto del 2020. Hprobado: 11 de septiembre del 2020

Artículo de reflexión

https://doi.org/10.25100/poligramas.v0i51.10898

\begin{abstract}
¿Cómo citar este artículo en MLH? - How to quote this article in MLA?
Tennina, Lucía. "La literatura brasileña de autoría negra y sus posicionamientos frente a las operaciones blancocéntricas del canon hegemónico" Poligramas 51 (2020): n. pág. Web.

Fecha de acceso (día, mes en mayúscula y abreviado, y año).
\end{abstract}

La figura de los autores y las autoras negras en la literatura brasileña parecería estar marcada por un manto de silencio que recién desde principios de este siglo, podríamos decir, empezó a tomar otra dimensión. En un país donde más de la mitad de la población es negra, a primera vista los escritores negros se pueden contar, a duras penas, con los dedos de una mano. El ejemplo más explícito en este sentido sucedió hace pocos años, en el 2013, cuando la Feria del Libro de Frankfurt recibió como literatura homenajeada a la literatura brasileña, por lo que se seleccionaron como representantes un total de 70 escritores elegidos por un comité curatorial, bajo el criterio de "mostrar um Brasil sem exotismos, mais contemporâneo, um Brasil mais moderno e inovador; tanto na literatura, quanto nos trabalhos artísticos da programação paralela" (Rodríguez párr. 1). Pero, en el medio de la celebración, surgió un debate. A una semana de inaugurada la Feria, el diario alemán Süddeutsche Zeitung publicó una nota en la que destacaba la hegemonía de escritores blancos, jóvenes y de clase media entre los 70 seleccionados para representar a Brasil, con la excepción de un solo negro, Paulo Lins, y un solo indígena, Daniel Munduruku (Von Metz párr. 1). Un tiempo después, el diario alemán Tagesspiegel publicó una entrevista a Paulo Lins, donde, haciendo referencia a aquel artículo, afirmaba: "Yo soy el único autor negro de esa lista. ¿En qué sentido eso no es racismo?" (Lichterbeck párr. 6).

Otro ejemplo, aún más reciente e igualmente elocuente, sucedió en abril del 2019, cuando uno de los espacios más importantes de investigación en cultura brasileña, el Instituto Moreira Salles, organizó un evento para debatir sobre la poesía contemporánea con la invitación de 18 poetas. El nombre del ciclo era "Oficina irritada (poetas falam)", bajo la curaduría del poeta y 
profesor de la UFR Eucanaã Ferraz, donde se pretendía reunir "importantes nomes da poesia contemporânea brasileira", durante seis encuentros de tres días, con la consigna de "responder às questões estéticas, históricas, éticas e afetivas do presente" (Evensi párr.. 4). A pesar de ese llamado a la diversidad, desde la preocupación ética en relación con el presente brasileño, de los 18 autores ninguno era negro. Esto no pasó desapercibido; este silenciamiento fue altamente criticado en las redes sociales y en ciertos medios de comunicación. Algunos poetas negros, de hecho, llegaron a replicar el cartel publicitario con la foto de algunas referencias de autoría negra que podrían haber participado (Arman, párr. 1). El evento se canceló, sin que la institución o sus organizadores se hiciesen cargo completamente del acto racista.

Esta invisibilización se replica hasta el día de hoy en las antologías que se organizan sobre literatura brasileña, en las colecciones en el extranjero, en los programas de las materias que trabajan sobre producciones contemporáneas, en los programas de los congresos, hasta hace no mucho tiempos atrás, etc., etc. El archivo de la literatura brasileña, entendiendo esta noción desde la definición foucaultiana de "la ley de lo que puede ser dicho, el sistema que rige la aparición de los enunciados" (Foucault 170), autoriza solamente la palabra blanca, pero al mismo tiempo está compuesto por silenciamientos que cada vez más tienen mayor resonancia.

En este artículo, me ocuparé de analizar un conjunto de poemas que dialogan con el canon de la literatura brasileña de diversos modos. El corpus de poemas que lo componen se concentra en autores del siglo XX: Carolina Maria de Jesus, Edimilson de Almeida Pereira, Eliane Marques, Oswaldo de Camargo, Cuti, Conceição Evaristo, Carlos Assumpção, Mel Duarte. Parto, asimismo, de una concepción ampliada de literatura, por lo que, junto con la literatura de autoría negra, haré mención también a prácticas culturales no literarias (como la fotografía y las artes plásticas). Para referirme a esta escena literaria, utilizaré la categoría de "autoría negra» acuñada por Regina Dalcastagnè, que desarrollaré en el segundo apartado. 


\section{«Cupos» de autores negros en la historia de la literatura brasileña}

Si bien el canon de la literatura brasileña se define desde su blancocentrismo, es posible registrar momentos en los que la emanación espectral ${ }^{2}$ de este archivo literario estrictamente blanco habilitó ciertos «cupos» para autores negros. La literatura brasileña, en tanto un tipo de ordenamiento que se pretende, estable una relación con la custodia de los orígenes y las emanaciones que ese archivo pueda producir, y habilita a lo largo de su historia la consignación de nombres de autores negros, en función de una pretendida diversidad controlada.

Un ejemplo es el caso del ya mencionado Paulo Lins, autor de Ciudad de Dios, publicado en 1997 por la editorial Companhia das Letras. El escritor de este best seller publicado por la editorial más legitimada en términos literarios de Brasil, bajo el ala protectora del crítico Roberto Schwarz, es un negro oriundo de la favela Ciudad de Dios, que se inicia en la narrativa con ese libro que relata la vida desde adentro de ese barrio que lo vio nacer. De acuerdo con Heloísa Buarque de Hollanda, más allá de la calidad literaria indiscutible de esta novela, la edición y la avidez del público frente a este libro tuvo que ver con que venía a responder a "... las demandas de la clase media vinculadas a un cierto interés de esas clases por los relatos sobre las favelas o los marginalizados sociales debido la intensificación de la violencia y los enfrentamientos policiales que se multiplicaban en las periferias urbanas" (277). Algunos de esos episodios fueron tristemente emblemáticos, como la masacre de la Candelaria, en Rio de Janeiro, en 1993, con el asesinato brutal en manos de la policía de ocho niños, de los 50 que dormían en las escalinatas de la iglesia. Otro fue la masacre, también en 1993, de Vigário Geral, una favela de Rio de Janeiro, donde la policía se paseó encapuchada matando gente, asesinando un total de 21 personas. Y otro fue un año antes, en 1992, en la cárcel de Carandiru, donde también sucedió una masacre con el saldo de 111 presos asesinados.

Otro ejemplo de «cupo» negro en el campo literario es el de Carolina Maria de Jesus y su Quarto de Despejo. Diário de uma favelada, cuya primera edición fue publicada en portugués, en agosto de 1960. Se trata de un diario sobre la vida en la favela Canindé, donde vivió esta mujer negra trabajando como cartonera. Esta publicación estuvo mediada por el periodista Audálio Dantas, quien también asumió el rol de agente literario en esos años. Es un libro que llama la

\footnotetext{
${ }^{2}$ La idea de emanación espectral que utilizaré a lo largo de este artículo se inspira en los estudios de Derrida sobre el concepto de archivo volcados en su libro Mal de archivo, donde asocia la idea de archivo, por un lado, a la pulsión de muerte, esto es, básicamente, la posibilidad de su desaparición como definitorio de este, y, también, a la idea de espectro, en tanto imagen que se reproduce en ausencia del acontecimiento (24). La emanación espectral se refiere, así, a todo aquello que el archivo no dice, pero sugiere; todo lo que desborda de ese archivo, las ideas que funcionan por fuera de él y a partir de él.
} 
atención por la dinámica que establece entre lo agobiante del día a día, a partir de la ecuación de la falta, pero que, al mismo tiempo, muestra la potencia de una mirada afectiva y afectada por la maternidad, la escritura y la naturaleza. Carolina Maria de Jesus tuvo un éxito enorme con su primer libro, la mayoría de los principales periódicos publicaron reseñas sobre la obra, que vendió ochenta mil ejemplares en Brasil el mismo año de su lanzamiento. Los círculos letrados brasileños, por primera vez, contaron en sus eventos con la presencia de una mujer negra y habitante de una favela, cuyo texto llegó a interesar a algunos de los escritores más reconocidos, como Clarice Lispector. El libro, además, empezó a ser traducido a menos de un año de su publicación y en cinco años ya estaba circulando por 16 países $^{3}$ : en 1961, por Dinamarca, Holanda y Argentina; en 1962, por Francia y Alemania (Occidental), Suecia, Italia, Checoslovaquia, Rumania, Inglaterra, Estados Unidos y Japón; en 1963, por Polonia; en 1964, por Hungría; en 1965, por Cuba, y, entre 1962 y 1963, por la Unión Soviética (Fenske párr. 9).

El lugar destacado que adquirió esta escritora en el campo literario de su época tuvo que ver, en gran medida, con el interés de los intelectuales hacia las experiencias de los sectores subalternos, a partir del triunfo castrista en Cuba, justamente cuando el espectro de la revolución popular empezó a recorrer el continente. En el caso de la publicación en Cuba, cabe destacar que la obra de Carolina Maria de Jesus fue publicada tan solo cinco años antes de que el premio literario Casa de las Américas (instaurado un año después de la Revolución cubana) inaugurara la categoría "testimonio», que fue impulsada por Ángel Rama (Rama 122-123). La publicación de Quarto de despejo. Diário de uma favelada se realizó en un contexto en el que su contenido respondía a la urgencia contextual asociada a las luchas sociopolíticas y en un momento en el que se estaban empezando a publicar varios libros que daban cuenta de ese tiempo histórico.

Pero la producción de la escritora de la favela de Canindé no interesó más allá de su primer libro. Tres años después de Quarto de despejo. Diário de uma favelada, publicó Casa de alvenaria Diário de uma ex-favelada, donde relata su vida después del éxito alcanzado, pero su repercusión fue casi nula, al igual que ocurrió con las publicaciones posteriores: Pedaços de fome y Provérbios (1963), publicado en vida, y, luego de su muerte, Diário de Bitita (1982), Meu estranho diario (1996) y Antologia pessoal (1996). Carolina María de Jesus nunca más volvió a tener el reconocimiento que obtuvo con su primera obra, a punto tal que murió, en 1977, olvidada por el campo literario y en situación de pobreza extrema. Como se puede leer en un poema que lleva el

\footnotetext{
${ }^{3}$ La investigadora Elzira Divina Perpetua llama la atención sobre las modificaciones del título en sus traducciones: en la traducción argentina, por ejemplo, se tradujo como Quarto de despejo. Diario de una mujer que tenía hambre; en Estados Unidos, Child of dark (Hija de la oscuridad); en Cuba se tradujo como Favela.
} 
mismo nombre que su primera novela, publicado en el libro Antologia Pessoa/y traducido en una reciente antología publicada en Argentina

Cuando me infiltré en la literatura/ Soñaba con la ventura/ Mi alma estaba llena de hianto/Yo no preveía llanto. / Al publicar Cuarto de desechos/Concretizaba así mi deseo./ Qué vida. Qué alegría./ Y ahora. Casa de albañilería./ Otro libro que va a circular/ Las tristezas se van a duplicar./ Los que piden que vaya a auxiliar/ A sus metas poder lograr/ Pienso: debería publicar.../ - Quarto de depósito.// Al principio vino la admiración/ mi nombre circuló por la Nación./ Surgió una escritora favelada./ Se llama: Carolina Maria de Jesus./ Y las obras que ella saca a la luz/ Dejó a la humanidad abismada// Al comienzo tuve confusión./ Parece que había una obturación En un alto paladín./ Me solicitaban./ Me lisonjeaban./ Como a un querubín.// Después comenzaron a envidiar./ Decían: vos, tenés que dar/ tus bienes, a un cobijo/ Los que así hablaban/ No pensaban/ En mis hijos.// Las damas de la alta sociedad./ Decían: praticae a caridad./ Donando a los pobres agasajos./ Pero el dinero de la alta sociedad/ No se destina a la caridad/ Es para los campos, los barajos/ Y así, me fui desilusionando/ Mi ideal retrocediendo/ Como un cuerpo envejeciendo./ Me fui arrugando, arrugando.../ Pétalos de rosa, marchitando, marchitando/ Y... jestoy muriendo! (De Jesus, Quilombo 16-18)

Este poema es un relato explícito respecto de la institución literaria ligada a las clases pudientes, el uso que se hizo de la figura de esta escritora desde un «interés antropológico» antes que estético, la responsabilidad frente a la condición de clase que se le impone y su condición de reemplazable, como si fuera un objeto que se usó y se desechó.

Yendo más atrás en la línea del tiempo, encontramos también otros autores negros reconocidos en diferentes momentos de la historia de la literatura brasileña. El más destacado de todos ellos es Machado de Assis, quien, como se sabe, es un autor central del canon. Pero llama la atención que este escritor sea recordado como escritor blanco. Ya en su obituario se puede ver esa descripción:

Olympio da Silva Pereira, official do registro civil e escrivão vitalício da 6 ta portaria do Distrito federal, em 29 de setembro de 1908 -Certifico que do livro de registros de óbitos sob numero cincoenta e dois consta, a folha 63, o registro de óbito de Joaquim Maria Machado de Assis: edade 69 annos, viuvo, natural desta capital, funcionario publico, cor branca, fallecido de arterio-esclero e, às 3 e 20 da manhã do dia 29 de setembro de 
1908, à residência do próprio finado, rua Cosme Velho 18. Deixou testamento (Correio da Manhã 30/09/1908).

Esta idea de Machado de Assis blanco no se tamizó con ninguna concesión políticamente correcta en los últimos años. Sin ir más lejos, en 2011, un banco muy conocido lanzó una publicidad televisiva en la que, para legitimar su prestigio a lo largo del tiempo, mostraba al escritor como un asiduo cliente. Pero ese hombre elegante vestido de traje, con anteojos y un bastón, era llamativamente blanco. Las reacciones no tardaron en llegar. El gesto racista era evidente, por lo que la publicidad fue retirada inmediatamente de circulación (Ramos párr. 1). Pero la conclusión de ese hecho quedó clara: Machado de Assis, en la imaginación de la mayor parte de los brasileños, sigue siendo blanco. Recién en 2019, empezó a repensarse institucionalmente el universo iconográfico alrededor de este escritor. Un nuevo proyecto, desarrollado por una agencia publicitaria y la Universidad Zumbi dos Palmares de São Paulo, recreó la fotografía que más circula del escritor y la intervino de manera tal que se notara su piel negra. El proyecto, llamado «Machado de Assis Real», apunta a alentar a los lectores a descargar e imprimir la nueva imagen, y publicarla en las redes sociales pegada sobre la imagen existente en sus libros, junto a la etiqueta \#MachadoDeAssisReal. Lo que se espera es que los editores comiencen a usar la nueva imagen en las portadas de los libros (Brito párr. 5).

Otro trabajo de recomposición o resignificación iconográfica destacable es el de una escritora negra, contemporánea a Machado de Assis -reconocida en la época, pero completamente olvidada luego-, Maria Firmina dos Reis, autora de la novela Úrsula, publicada en 1859. Hasta fines de 2012, la única foto que circuló de esta escritora, que es de hecho la que se encuentra en una primera búsqueda por internet hoy en día, es una foto falsa que se corresponde en realidad con la de una escritora blanca del sur de Brasil, Meria Benedita Câmara (Neiva párr. 1). No hay registros fotográficos de ella, solo confusiones respecto de su imagen. Es por eso que la Festa Literária das Periferias le prestó homenaje en el 2018 y abrieron un concurso para recrear el rostro de la escritora, a partir de los testimonios que se tienen sobre ella. La imagen ganadora fue realizada por el artista João Gabriel dos Santos Araújo.

Otro escritor ineludible, al hacer referencia a escritores negros que lograron su inscripción en la historia de la literatura brasileña, es Lima Barreto, un escritor que militaba por los derechos de su grupo social, a diferencia de Machado, que no tenía como tema directamente la cuestión negra. Este escritor no fue del todo aceptado en el campo literario hasta muchos años después de su muerte. Su novela más importante, Triste fim de Policarpo Quaresma (1915), por ejemplo, 
fue editada con grandes dificultades por el propio autor, sin intermediación de ninguna casa editorial (hecho que en esa época ya se acostumbrada) y no fue reeditada en vida. La figura de Lima Barreto y su propia escritura estuvieron siempre en un lugar marginalizado. Este escritor solo pasará a ser incorporado a la llamada historia de la literatura brasileña a partir de la publicación, en 1956, por la editorial Brasiliense, de las Obras completas, organizadas por Francisco de Assis Barbosa con la colaboración de Antônio Houaiss y Manuel Cavalcanti Proença. En 1952, Assis Barbosa publicaría la primera edición de la biografía, realizada luego de muchos años de investigación, donde atribuye la marginalización de este escritor dentro del canon directamente a su origen social negro.

\section{Literatura de autoría negra. La conformación de un circuito y una escena}

Recién en los años 80, cuando los escritores empiezan a conformar un circuito y una escena propia, independiente y autogestionada, es cuando la producción de autoría negra empieza a adquirir cierta visibilidad. Y cabe aclarar que esta visibilidad no solamente alcanzó a los productores, sino también a los lectores: a partir de ese momento empieza a conformarse un público lector negro. Hago la distinción entre "circuito" y "escena», en tanto el primero refiere a la oferta de determinado servicio por medio de una estructura física (establecimientos, editoriales, espacios, etc.) y el segundo remite a un conjunto de comportamientos (pautas de consumo, gustos) y universo de significados (valores, reglas) exhibidos y cultivados por quienes frecuentan los circuitos (Magnani 21, 251).

Un marco importante para esta instancia literaria se dio a fines de la década del 70 del siglo XX, más precisamente en 1978, cuando en las escaleras del Teatro Municipal de São Paulo surge el Movimiento Negro Unificado contra la Discriminación Racial. Ese mismo año, unos meses después, se lanza el primer volumen de la serie Cadernos Negros. Desde entonces, Cadernos negros inició sus publicaciones de cuentos y poesías de autores negros (hoy en día ya han publicado 42 números). Esas publicaciones tenían como propósito fundamental postular una "estética negra», siguiendo el camino trazado por Solano Trindade, entre otros (Cuti, Literatura negro-brasileira 28-29). Hasta ese momento, el estudio de la llamada «literatura negra» había sido objeto de interés de investigadores extranjeros como Roger Bastide (1943), Raymond Sayers (1956), por nombrar a los más destacados (Medeiros da Silva 276).

La publicación de Cadernos Negros contribuyó no solamente al montaje del circuito y a la conformación de la escena, sino también a la configuración discursiva del concepto de literatura 
negra. Ironides Rodríguez, uno de los intelectuales más destacados del grupo, la define de este modo: "A literatura negra é aquela desenvolvida por autor negro ou multado que escreva sobre sua raça dentro do significado do que é ser negro, da cor negra, de forma assumida, discutindo os problemas que a concernem: religião, sociedade, racismo. Ele tem que se assumir como negro" (ctd. Em De Assis Duarte 370). Tal y como señala De Assis Duarte, la postura del grupo de Cadernos Negros en relación con la definición de la literatura negra delinea un programa rígido y explícito, en el que, al tiempo que se agruparon a muchos escritores que se identificaron con este posicionamiento, muchos otros se distanciaron por estar en una línea menos militante.

Esta idea de «literatura negra» exige repensar otros dos conceptos, de los cuales se diferencia. Uno de ellos es el de «negrismo» y otro es el de «literatura afro brasileña». El concepto de negrismo se liga a la tradición modernista de los años 20 en Brasil (Schwartz 659), donde es posible mencionar autores que se preocuparon por tematizar la población negra en Brasil, como Raul Bopp (Urucungo, 1932), Jorge de Lima (Poemas negros, 1947) y Ascenso Ferreira (con poemas como "Maracatu» de 1941). El negrismo está en consonancia con el indianismo del período romántico, en el sentido de que se trata de experiencias literarias en las cuales los escritores blancos empiezan a pensar la identidad brasileña incorporando al «otro». El negrismo incorpora la figura del negro de forma tal que lo vuelve, en palabras irónicas de Oswald de Andrade, una "macumba para turistas" (95), es decir, que reduce al negro a un objeto de la fantasía del colonizador.

Otro concepto que es necesario explorar al hacer referencia a la producción de autoría negra es el de literatura afrobrasileña. Se trata de una denominación que hace referencia a las raíces africanas de estos textos y escritores. El grupo Quilombhoje, colectivo que edita los Cadernos Negros, rechaza este concepto debido a la dependencia que demanda respecto del origen, alejándolo de la literatura brasileña. En palabras de Cuti:

Denominar afro a produção literária negro-brasileira (dos que se assumem como negros em seus textos) é projetá-la à origem continental de seus autores, deixando-a à margem da literatura brasileira (...) para se fazer da vertente negra um mero apêndice da literatura africana. Em outras palavras, é como se só a produção de autores brancos coubesse compor a literatura do Brasil (Literatura negro-brasileira 35-36).

Por su parte, uno de los más importantes académicos en el campo del estudio de la literatura de autoría negra, Eduardo Assis Duarte, de la Universidad Federal de Minas Gerais, prefiere asumir el concepto de literatura afrobrasileña, en tanto dice que ese concepto puede 
abarcar también a aquellos autores (como Machado de Assis o Maria Firmina dos Reis) que no tienen como marca de origen explícita su origen negro, sino que más bien trabajaron por su ocultamiento. En este sentido, el término afrobrasileño resulta más elástico, según este investigador: "inscreve-se como um operador capacitado a abarcar melhor, por sua amplitude necessariamente compósita, as várias tendências existentes na demarcação discursiva do campo identitário afrodescendente em sua expressão literária" (374).

Pensando justamente en la elasticidad respecto de sus producciones literarias, pero no respecto de su pertenencia al grupo social negro, algunos estudiosos de estas producciones (como Regina Dalcastagnè, 2015) eligen utilizar el concepto de «literatura de autoría negra», concepto que desplaza el adjetivo negro hacia la propia autopercepción del grupo étnico de pertenencia de los autores. En este artículo, de hecho, ese será el término que mantendré, en tanto corre el debate de la dependencia continental y de la exclusividad temática.

Una pregunta que suele aparecer a la hora de reflexionar sobre estos conceptos apunta a cuestionar el porqué de la búsqueda por una adjetivación. El argumento más común para este tipo de cuestionamientos parte de la afirmación de que no se dice que un escritor blanco-brasileño produce literatura eurobrasileña, ni tampoco blanco-brasileña. ¿Por qué, entonces, el destaque de negro-brasileña? Porque la idea de brasileña, de literatura y de cultura, como intenté mostrar desde el comienzo de este artículo, todavía, son blancas. Generalizar e intentar borrar la distinción es un acto, disimulado, de racismo. El acto de nombrar y distinguirla visibiliza y otorga valor a estas producciones. En palabras de la poeta y profesora Lívia Souza Santos:

Sim, a literatura tem sobrenomes, e são muitos: homoafetiva, feminina, negra, periférica, oral. Cada um deles engendra um campo de diferenças constantemente silenciadas e caminham na contra mão, pela afirmação da diferença e negação da identidade unívoca uma vez que ela corresponde àquele que se pensa como o neutro, o apaziguador, o não-marcado que, ao fim e ao cabo, nada mais é que uma simulação de presença pura, igual a si mesmo que só admite ladear-se de outros objetos narcisicamente interiorizados, literaturas sem marcas, sem sobrenomes, mas com nomes próprios potentes o suficiente para solapar qualquer diferença. Assim, defendemos a força não essencializante dos sobrenomes como incidentes ou acontecimentos literários que não aprisionam a leitura a um condicionamento limitado e imediatista, uma vez que não devem ser pensados como novos centramentos fixos, como outras formas de apagamento da diferença, mas como centros instáveis e inseguros que preservam a capacidade que toda expressão artística tem de se oferecer ao mundo em ininterrupto devir. Na cena da 
possibilidade pura, a nomeação deseja mais abrir um flanco para o exercício das diferenças radicais, para a exposição das subjetivas como clave possível de leitura de mundo (111).

La adjetivación apunta hacia la pretensión universalizante y objetiva del concepto de literatura y hacia el develamiento de que, por detrás de esas operaciones, hay silenciamientos y violencias que son necesarios nombrar y distinguir.

\section{La literatura de autoría negra en la arena pública}

No hay dudas de que en los últimos casi veinte años la situación en relación con el silenciamiento de la producción cultural del grupo social negro cambió bastante. En gran medida, debido a las acciones afirmativas en términos de políticas públicas en función de ampliar, desde una justificación de reparación histórica, la presencia de estudiantes negros (e indígenas) en las universidades, a partir de la implementación de una política de cupos; hecho que impactó directamente en los debates en las aulas y en la bibliografía de los programas de estudio. A diferencia de los «cupos» analizados en el primer apartado de este artículo, esta idea de «cupos», vinculada a una política pública, adquiere una connotación positiva en tanto apunta no a un gesto políticamente correcto, sino a un horizonte de democratización de alto impacto. La primera propuesta de implementación de cupos raciales en Brasil fue presentada durante la semana de la conciencia negra, en noviembre de 1999, en la Biblioteca Central de la Universidad de Brasília, por Rita Segato y José Jorge de Carvalho, y sería aprobada en el 2003 e implementada en el $2004^{4}$.

El mismo año en que se aprobó la implementación de los cupos raciales, se aprobó la Ley 10.639, que obliga a incluir en los programas de estudio oficiales de enseñanza la temática "historia y cultura afrobrasileña y africana». Se trata de un proyecto que había sido presentado en 1999 por los diputados Ester Grossi (educadora de RGS) y Bem-Hur Ferreira (militante del movimiento negro), pero que fue aprobado el año de la asunción del presidente Lula da Silva, el 2003.

Es en este contexto donde, paralelamente al trabajo que venía haciendo el grupo Cadernos negros y sus ramificaciones, desde el campo literario, se comenzó un trabajo de rescate de escritores y escritoras negros olvidados en los últimos años, como Carolina Maria de Jesus, Maria Firmina dos Reis y Lima Barreto. Lima Barreto, por ejemplo, fue el autor homenajeado en el 2017.

\footnotetext{
4 La propuesta presentada se puede revisar en este documento preparado por la Universidad: http://www.dan.unb.br/images/doc/Serie314empdf.pdf. 
año en el que la historiadora Lilia Moritz Schwarcz publicó una nueva biografía por la editorial Companhia das Letras. La novela Úrsula obtuvo una gran cantidad de reediciones (por dar algunos ejemplos, en el 2018 la reeditó Companhia das Letras; en el 2018, la editorial ZOUK; en el 2019, Câmara Edições; en el 2020, PUC Minas Ediciones) y muchos otros homenajes, como el ya mencionado de la Festa Literária das Periferiasd (FLUP) en el 2018.

De todos modos, todavía, la emanación espectral respecto de la literatura sigue siendo blancocéntrica, es decir, que sigue siendo pensada desde las perspectivas y los conceptos de un posicionamiento de sujeto blanco ${ }^{5}$. Cuando se trata de literatura negra, por ejemplo, parece no haber otro interés más que en la cuestión étnica respecto del escritor; hecho que no sucede cuando se trata de un escritor blanco, dado que es incuestionable el lugar del escritor blanco en el campo literario. Por otro lado, muchas veces, la producción de autoría negra se lee agrupadamente, como si sus producciones estuvieran en relación, más allá de las abismales diferencias temáticas, de estilo, de género, de época. Además, sigue primando una especie de sorpresa ante la existencia de un escritor de autoría negra, como si esa profesión no le perteneciera del todo, y a esta sorpresa le sigue una romantización de su figura, reacción que esconde, en última instancia, un acto de racismo. Sucede que lo que se espera del grupo social negro no es que sea un escritor profesional y esto se ve tematizado, claramente, en el modo en que construyen los personajes negros en las publicaciones de literatura brasileña. Quien ha profundizado desde una novedosa perspectiva cuantitativa ${ }^{6}$ sobre estos aspectos, en relación con las producciones contemporáneas, es la investigadora Regina Dalcastagnè. Esta profesora de la Universidad de Brasilia publicó en el 2005 una investigación titulada «Personajes de la novela brasileña contemporánea», en la que, con base en un corpus de 258 novelas publicadas, entre 1990 y 2004, por las tres editoriales más importantes de Brasil (Rocco, Companhia das Letras y Record), desarrolló un estudio estadístico que tomó en cuenta el color y la posición de los personajes, las principales ocupaciones, el estrato socioeconómico, la franja etaria, etc. Las conclusiones a las que llegó fueron contundentes:

\footnotetext{
${ }^{5}$ Una parodia perfecta para comprender este posicionamiento blancocéntrico es el video realizado por la productora Porta dos Fundos, titulado "Escritor branco». Disponible en https://www.youtube.com/watch? $v=2 s 7 W T h 3 \mid z B Q$ (acceso en agosto del 2020).

${ }^{6}$ Cabe destacar que las operaciones metodológicas que posibilitaron esta investigación se aproximan a la idea de "lectura distante», trabajada por Franco Moretti y su literatura mundial, quien la define del siguiente modo: "(...) el problema con la lectura cercana (...) es que requiere necesariamente un canon minúsculo (...) Y si queremos ver qué hay más allá del canon (y la literatura mundial tiene que hacerlo, por supuesto: ¡Sería absurdo que no lo hiciera!), la lectura cercana no servirá (...) ya sabemos leer textos, ahora tenemos que aprender a no leerlos. Lectura distante, donde la distancia, cabe repetir, es una condición del conocimiento; es lo que permite colocar el foco en unidades mucho más pequeñas o mucho más grandes que el texto" (63).
} 
La literatura contemporánea refleja en sus ausencias tal vez más aún en lo que expresa, algunas de las características centrales de la sociedad brasileña. Es el caso de la población negra, que siglos de racismo estructural apartan de los espacios de poder y de producción del discurso. Son pocos los autores negros y pocos, también, los personajes: una amplia investigación con novelas de las principales editoriales del país publicadas a partir de 1965 identificó casi 80 \% de personajes blancos, proporción que aumenta cuando se aíslan protagonistas y narradores (49).

Sumada a la alarma que pueden causar los porcentajes de proporción de personajes negros que esta investigación logró evidenciar, las estadísticas profundizan más esa distancia estructural al revelar las "principales ocupaciones de los personajes". Mientras que los personajes blancos son principalmente amas de casa, artistas, escritores, estudiantes, etc., los personajes negros son bandidos, empleadas domésticas, esclavos, profesionales del sexo, etc. (57). La literatura es, así, un espacio donde se validan representaciones del mundo social camufladas, muchas veces, bajo pretensiones de realismo o de atención a los recursos estéticos.

El manto de sospecha que recae sobre las personas negras en su vida cotidiana es un elemento central que se tematiza en la literatura de autoría negra. Un ejemplo ineludible es el poema "Quebranto», del ya citado escritor paulista Cuti, uno de los fundadores de la serie Cadernos Negros.

a veces soy un policía que me sospecho / me pido documentos / y por más que los tenga / me arresto / y me doy una paliza // a veces soy el portero / que no me deja entrar en mí mismo / a no ser / por la puerta de servicio // a veces soy mi propio delito / el cuerpo de los jurados / el castigo que viene con el veredicto // a veces soy el amor que me da vuelta la cara/ el quebranto / la mala sombra / la soledad primitiva / que me envuelvo con el vacío // a veces las migas de lo que soñé y no comí / otras el benteveo de ojos vidriados / trinando tristezas // un día fui abolición que me lancé de sopetón en el espanto / después un emperador depuesto / la república de las confabulaciones en el corazón / y enseguida una constitución / que me promulgo a cada instante // también la violencia de un impulso / que me pongo dado vuelta / con accesos de cal y de yeso / llego a ser // a veces me las arreglo para no verme / y entupido con la visión de ellos / me siento la miseria concebida como un eterno comienzo // me cierro el cerco / siendo el gesto que me niego / el aguafuerte que me bebo y me emborracho / el dedo que me señalo / y denuncio / al punto que me entrego // a veces... (Quilombo 42-43). 
Este poema habla, tal y como se puede percibir, -en reflexivo del verbo sospechar- de que la sospecha no siempre está en un afuera, en un otro. Acá la sospecha está claramente internalizada, se trata de una culpabilidad apriorística. Como señala Pierre Bourdieu, "la probabilidad de sentirse incómodo en el cuerpo de uno (...), el malestar, la timidez o la vergüenza son tanto más fuertes en la medida en que es mayor la desproporción entre el cuerpo socialmente exigido y la relación práctica con el cuerpo que imponen las miradas y reacciones de los demás" (85). El cuerpo negro no es el socialmente exigido por el estereotipo de ciudadano, sino que es el socialmente rechazado, y ese rechazo se termina incorporando, como relata el poema de Cuti. Como dice la artista e investigadora portuguesa Grada Kilomba: "corpos negros são construídos como corpos impróprios, como corpos que estão 'fora do lugar' e, por essa razão, corpos que não podem pertencer" (56). Pero lo interesante en este poema es que el uso del "a veces» final, seguido de puntos suspensivos, genera un doble sentido, porque, sumado a la carga de angustia que arrastra durante todo el poema, en tanto no se sabe cuándo va a suceder la autocensura, también se puede pensar que ese final inconcluso y en suspenso le otorga fuerzas, dejando un aire de esperanzas en relación con otra posibilidad de reacción por parte del yo lírico.

\section{Resignificaciones del archivo de la esclavitud}

De la misma manera que el grupo social negro tiene incorporada la culpabilidad, el grupo social blanco tiene incorporado el racismo, y resulta un trabajo de desaprendizaje constante descomprimir esa carga. Un ejemplo que dé cuenta de esto se puede encontrar en las lecturas muchas veces amenas respecto del tratamiento de la población negra y esclava por parte de los grandes representantes de la historia literaria y del arte brasileños. El período de las vanguardias es uno de los períodos que deben ser releídos, todavía, en un sentido antirracista, por más que en sus postulados se suponga una operación de democratización de las artes y el lenguaje. El cuadro "A negra" (1923), de Tarsila do Amaral, es el caso que más permite este ejercicio. Tarsila es, sin dudas, una de las artistas más destacadas de la historia de las artes visuales brasileñas a nivel mundial. Se trata de una artista que, en sintonía con la línea de intereses de las vanguardias brasileñas, se aboca hacia temáticas ligadas a la cultura popular y a las segregaciones que la industrialización del país conlleva. En este sentido, parte de su producción investiga un conjunto de manifestaciones culturales agrupadas alrededor de la idea de "arte y culturas negras». Su obra "A negra" se incluye dentro de esos intereses. Ahí se puede ver la imagen de un ama de leche, con los senos al aire y una representación corporal ligada a la geometría del arte de vanguardia. 
Sin dudas, este cuadro es de extremo interés para pensar los vínculos del arte brasileño y las vanguardias europeas, o para discutir el concepto de representación en un sentido vanguardista. Pero no deja de llamar la atención lo que devela la artista en sus diarios (Abdala y Amaral 92), al hacer referencia a la existencia efectiva de este modelo: la mujer retratada en el cuadro es el ama de leche que acompañó a la propia Tarsila en su infancia. De esta mujer existe, de hecho, una fotografía que Tarsila reproduce en ese texto, donde se puede ver a la mujer en la misma posición retratada en el cuadro, aunque vestida. Leído desde un punto de vista que no anule la cuestión racista, es notable el trabajo que hace Tarsila sobre la fotografía de esa mujer. En primer lugar, le quita la ropa, los cabellos y acentúa extremadamente los trazos faciales propios del fenotipo negro, exotizándola. La deshumanización de esta imagen se lleva al punto tal de que pasa a ser "La Negra», por más que tuviese un nombre. Este tipo de operaciones de lectura, paralelamente a las valoraciones estéticas, son necesarias para acostumbrar el ejercicio crítico a no esconder en una supuesta objetividad las emanaciones espectrales del archivo racista que constituye la cultura brasileña.

En la literatura, el trabajo de archivo no romantizado respecto de la esclavitud por parte de los autores negros apunta, justamente, a frenar la reproducción de esa emanación espectral. Un ejemplo contundente es el poema "6" de la escritora oriunda de Rio Grande do Sul, Eliane Marques, publicado en el libro e se alguém o pano, en el 2015, y traducido al español para la antología Quilombo:

6

Mil reis a quien (con vida) a sus dueños (la familia brochado) brazo de la hacienda.

La señora sin hambre y fuertes dolores en el pecho.

La negrita en la primera noche de abril; en su posesión, el farol a querosén de la cocina.

Huesuda alta la cabeza trenzada.

La boca un pote de tierra.

Todavía con ángeles mahometanos y otras pavadas.

Atrevida. Desconoce el dinero.

Por el nombre de Justina tal vez aún atienda (93).

Este poema toma como material uno de los avisos de periódico comunes en el período de la esclavitud sobre esclavos fugitivos, esos avisos que el célebre personaje Candido del cuento «Padre contra madre» de Machado de Assis utilizaba para su oficio de cazador de esclavos. Se trataba de publicaciones que los dueños de los esclavos hacían en los periódicos denunciando la 
fuga de alguno de ellos y ofreciendo una recompensa para quien lo lograra encontrar. El anuncio en este poema está tomado casi textualmente, aunque está intervenido en la disposición del texto en versos y estrofas, en la estetización en itálicas del nombre de Justina y, sobre todo, en la eliminación de todos los verbos. Solamente dos verbos se mantienen en el texto, «desconoce» y "atienda», que se relacionan entre sí por su oposición. Uno tiene que ver con el desconocimiento, la no atención, y el otro con todo lo contrario, destacando así la dinámica de anulación o complementariedad de los contrarios.

Es interesante remarcar el trabajo de apropiación, vaciamiento y resignificación del archivo que se lleva a cabo en este poema. En primer lugar, la apropiación remite a la propiedad y a un sujeto propietario, que, en este caso, pasaría a ser la propia autora del libro. Habría, así, un pasaje de dominios que, en este caso, tiene que ver con un documento de la esclavitud. A esta operación le sigue el vaciamiento, en el sentido de un desentendimiento de los contenidos de un objeto que lo vuelven un archivo disponible, en tanto punto de partida para pensar el presente (Jameson 170). Finalmente, la operación de la resignificación de la esclavitud en diálogo con un sistema discursivo operado desde otro a priori histórico.

Otro ejemplo vinculado a la no reproducción del espectro racista de los textos artísticos vinculados a la esclavitud es un poema titulado "Atitude», de Oswaldo de Camargo, un poeta paulista también vinculado a los orígenes de los Cadernos Negros y que publicó dicho texto en 1978, en el primer número de esa colección. Este poema dialoga directamente con el conocido "Navio negreiro», de Castro Alves, poema épico dramático del siglo XIX que integra la prosa abolicionista de la época, cuyo comienzo dice "Estamos em pleno mar. Era um sonho dantesco. O tombadilho. Que das luzernas avermelha o brilho. De sangue a se banhar" (24). El poema de Oswaldo de Camargo dice lo siguiente: "Eu tenho a alma e o peito descobertos/ À sorte de ser homem, homem negro/ Primeiro imitador da noite e seus mistérios. / Triste entre os mais tristes, útil / Como um animal de rosto manso. / Muito agonia boia nos meus olhos, / Inspiro poesia ao vate branco: / '[...] Stamos em pleno mar [...]' / Estamos em plena angústia! ..." (ctd. en Cuti, Literatura negro-brasileira 112).

Nuevamente tenemos aquí una polarización, aunque ya no de verbos, como en el caso del poema de Marques, sino del lugar de habla. Como señala Cuti en relación con ese poema: "O texto do poeta romântico é sobre o escravo. A dicção de Camargo é a partir de um "eu" que já não é objeto do discurso do outro, mas sujeito de seu próprio discurso, revelando a situação vivenciada de ser negro em um navio negreiro e após a Abolição: angústia" (Cuti, Literatura negrobrasileira 112). Las emociones por el ser negro después de la esclavitud, en este poema, remiten 
a una sensación de continuidad de la esclavitud en el presente, como si ese yo lírico estuviese aún en un navío negrero. La esclavitud, aquí, parece seguir persistiendo y siendo sostenida en el tiempo presente, no es algo del pasado.

Ahora bien, el pasado esclavo también se aborda, en la literatura, desde una perspectiva afectiva y desde ahí se realiza la operación de anulación del espectro racista. Un ejemplo de este acercamiento es el poema "Voces-mujeres», de la escritora oriunda del estado de Minas Gerais, Conceição Evaristo, publicado en el 2008 en su libro Poemas da recordação e outros movimentos y traducido al español en la antología Quilombo (2019):

La voz de mi bisabuela / resonó pequeña / en las bodegas del navío. / Resonó lamentos / de una infancia perdida. // La voz de mi abuela / resonó obediencia / a los blancos-dueños de todo. // La voz de mi madre / resonó débilmente revuelta / al fondo de las cocinas ajenas / debajo de los estropajos / ropas sucias de los blancos / por el camino de barro / rumbo a la favela. // Mi voz aún / resuena versos perplejos / con rimas de sangre / y / hambre // La voz de mi hija / recorre todas nuestras voces / se recoge en sí / las voces mudas calladas / atragantadas en las gargantas.//La voz de mi hija / se recoge en sí / la palabra y el acto.// El ayer - el hoy - y el ahora. / En la voz de mi hija / se hará escuchar la resonancia / y el eco de la vida-libertad (Quilombo 29-30).

El pasado esclavo es retomado, en este poema, ligado a la palabra y la memoria. Este poema asume a la palabra y sus ecos como un camino hacia la "vida-libertad», a partir del proceso de una memoria vinculante que transita de un espacio-tiempo a otro, de un individuo a otro, dentro de un mismo grupo de referencia, que aquí son las mujeres negras. La vida-libertad negra se define, entonces, desde una idea de memoria que se asume como resistencia y resiliencia de una voz que resuena. No se trata de una reconstrucción de partes, de pedazos de historia pasada (porque este poema parte de la ruptura irremediable entre historia y memoria), sino de una memoria vinculante, fruto de un proceso colectivo basado en experiencias traumáticas y extremas. La vida-libertad, en este sentido, es pensada en plural, no en singular, y desde una perspectiva decolonial, en tanto traza una nueva manera de comunicación cultural desde adentro y no desde afuera, que busca ser escuchada y liberada. De lo que se trata, en definitiva, es de un ejercicio de reminiscencia (Zumthor 33-34) a partir del cual, a través de la tradición oral, se puede volver al pasado, recuperar raíces, costumbres ancestrales, voces, y reconstruir así su presente-futuro. 
Además de la voz, el vínculo con el pasado esclavo se manifiesta en algunos poemas de autoría negra a través del cuerpo, como se puede percibir en el poema del poeta paulista Carlos de Assumpção titulado «Batuque»:

Tengo un tambor / Tengo un tambor /Tengo un tambor /Tengo un tambor /Dentro del pecho /Tengo un tambor /Todo adornado de cintas /Rojas negras amarillas y blancas /Tambor que bate /Batuque batuque bate /Tambor que bate /Batuque batuque bate /Que evoca la bravura de nuestros abuelos /Tambor que bate /Batuque batuque bate /Tambor que bate /Batuque batuque bate /Tambor que bate/El toque de reunir/A todos los hermanos /De todos los colores/Sin distinción //Tengo un tambor /Tengo un tambor /Tengo un tambor /Tengo un tambor /Dentro del pecho /Tengo un tambor //Todo adornado de cintas /Rojas negras amarillas blancas azules y verdes//Tambor que bate /Batuque batuque bate /Tambor que bate /Batuque batuque bate /Tambor que bate /El toque de reunir /A todos los hermanos /Dispersos /Lanzados a senzalas de dolor /Tambor que bate /Batuque batuque bate /Tambor que bate /Batuque batuque bate /Tambor que habla de odio y de amor /Tambor que bate sonidos cortos y largos/Tambor que bate /Batuque batuque bate /Tambor que bate /EI toque de reunir /A todos los hermanos /De todos los colores //En un quilombo /En un quilombo /En un quilombo / Tengo un tambor /Tengo un tambor /Tengo un tambor // Tengo un tambor/Dentro del pecho/Tengo un tambor (19-21)

Este poema nos sitúa frente a un aspecto central de la literatura de autoría negra: el cuerpo. De la misma manera que sucede con el poema de Conceição Evaristo, donde el elemento vinculante es la voz, aquí el elemento ligado a la memoria, al afecto y a la comunidad es el cuerpo en tanto instrumento. El cuerpo, aquí, es un elemento de composición y la onomatopeya del golpe del tambor remite también a la materialidad de la palabra. La poesía es un complejo semiótico relativo al cuerpo y a su expresividad.

Ahora bien, paralelamente a las formas varias de pensar el archivo de la esclavitud y sus emanaciones en el presente, a través de la ancestralidad y del cuerpo, en todos estos resulta clave la atención alrededor de las articulaciones de la palabra. La palabra como herramienta definidora y estructurante. Dice, en este sentido, el poema "El grito», de Edimilson de Almeida Pereira:

La palabra viene siendo el lugar donde montamos refugio. En la plantación, en las mineras, tejemos el grito, origen de lo que hablamos. Lo que fue origen de la rebeldía, no 
se aplacó, irrumpe en las páginas, desnorteando los perros de caza. El grito acecha por detrás de la escritura, no confía en indicaciones, elige los atajos. Los perros aprendieron a espantar las noches y el tiempo. La palabra, sin embargo, es un edificio y se ensancha hacia los márgenes de la floresta (82).

Este poema, que es una especie de oda a la palabra, incorpora el término "grito», su forma más extrema y visceral. La forma de expresión que manifiesta lo que esta no puede decir, la forma que tiene la vocalidad de ensanchar los márgenes de la palabra. Es ese tipo de recorrido que hace la palabra de ese nosotros el que remite directamente a un pasado esclavo compartido.

\section{La palabra de mujer negra brasileña}

Conceição Evaristo plantea una diferencia entre la modulación de la palabra del escritor negro respecto de la escritora negra. En ese sentido, no habla de "grito", como Edimilson Pereira, sino de "escrivivência", término que se volvió ya un concepto adoptado por las escritoras negras y sus estudiosos. Dice Evaristo:

Assenhoreando-se "da pena", objeto representativo do poder falo-cêntrico branco, as escritoras negras buscam inscrever no corpus literário brasileiro imagens de uma autorepresentação. Surge a fala de um corpo que não é apenas descrito, mas antes de tudo vivido. A escre (vivência) das mulheres negras explicita as aventuras e as desventuras de quem conhece uma dupla condição, que a sociedade teima em querer inferiorizada, mulher e negra (Gênero e etnia 6).

La experiencia, así, estaría ligada a la escritura de un cuerpo a partir de una vivencia negra en Brasil; o sea, la mujer negra escribiendo a partir de su vivencia en la sociedad brasileña. Un poema esclarecedor al respecto es "Carolina a la hora de la estrella», de la misma Conceição Evaristo, publicado inicialmente en el 2008 en Gênero e etnia:

En medio de la noche / Carolina corta la hora de la estrella. /En los lazos de su familia un nudo /-el hambre./José Carlos mastica chicles./En su cumpleaños, Vera Eunice desiste/de un par de zapatos,/quiere un par de anteojos oscuros./João José en el via-crucis del cuerpo,/un soplo de vida en el instante ya/extinguiendo sus jóvenes días./Y allá Carolina./con los ojos profundos,/macabeando todos los dolores del mundo.../En la hora de la estrella, Clarice ni sabe/de una mujer que cartonea letras y escribe:/“De día tengo sueño y de noche poesía" (31). 
En este poema, la vida de Carolina Maria de Jesus se lee desde referencias que remiten a Clarice Lispector. Aparecen secuencias o títulos de las obras de estas dos escritoras en un cruce que las ubica en un diálogo de perspectivas sociales distintas. Todas las referencias que en Clarice remiten a experimentaciones en torno a los límites de la subjetividad y la palabra, acá se llevan al nivel de la sobrevivencia más extrema. ¿Será que el poema muestra la forma de comprender a Clarice por parte de una lectora como Carolina o, más bien, la imposibilidad de leerla? El poema puede, también, dar a entender todo lo que es imposible de contar desde el "saber» de Clarice, provocando una reflexión sobre la necesidad de ligar el lugar de habla a la representación.

En este punto, se presenta un tema fundamental ligado a la cuestión de la representación y la representatividad o no representatividad, de acuerdo con las perspectivas sociales en cuestión. El feminismo negro viene trabajando mucho esta problemática en función de pensar las varias posibilidades de ser mujer y de que sus representaciones sean representativas a partir del lugar de enunciación, sin que por ello se caiga en la exotización. El lugar de enunciación tiene que ver con el posicionamiento respecto de la normatización hegemónica de las identidades y, en este sentido, no solamente tiene que ver con una autodefinición, sino también con el develamiento de las operaciones de opresión y de privilegio. Este debate suma una invisibilidad más al archivo de la negritud, que es la de la mujer negra. En palabras de Grada Kilomba:

As mulheres negras foram assim postas em vários discursos que deturpam nossa própria realidade: um debate sobre o racismo onde o sujeito é homem negro; um discurso de gênero onde o sujeito é a mulher branca; e um discurso sobre a classe onde "raça" não tem lugar. (...)Tais narrativas separativas mantém a invisibilidade das mulheres negras nos debates acadêmicos e políticos (56).

Es a partir de estas múltiples violencias que menciona la cita, que el feminismo negro habla de un feminismo «interseccional», concepto acuñado por la norteamericana Kimberlé Crenshaw (1980) y adoptado fundamentalmente por el feminismo negro. La perspectiva interseccional considera múltiples interrelaciones entre las opresiones, entre las que se encuentran no solamente el poder masculino, sino el poder masculino negro y el feminismo tradicional, cuyo discurso está construido con base en la experiencia de la mujer blanca. La relectura no espectral del archivo desde la literatura negra se amplía, así, hacia la diferenciación de otro posicionamiento de sujeto, que es el de la mujer negra y la articulación amplificada de esa voz, como se puede leer en el siguiente poema, titulado «Nos quieren callar», de Mel Duarte, una poeta joven de São Paulo: 
Aquí estamos nosotras / Dueñas de nuestras propias palabras / Revolucionarias de lo cotidiano / Regando la tierra otrora abatida por nuestras antepasadas,/ Firmando nuestras huellas, sabiendo que hoy/ Cada vez que nuestras voces se propagan,/ Equivalen a diez que antes fueron silenciadas./ Mujeres de una generación atrevida/ Hijas de los saraus y las batallas de poesía/ Alquimistas/ Libertarias/ Propagandistas de la oralidad/ Compartiendo nuestras travesías/ Aclamando/ Siempre sembrando esta tierra verbo-fértil/ Perpetuando nuestra existencia/ A través de versos/Escribimos cuantos poemas/ Manifiestos/Sean necesarios por día/ Para que cada vida interrumpida/ Tenga más valía/ No más invisibles/ No más mercancía/ Si nos quieren privar,/ ocuparemos espacios/ Si nos quieren borrar,/ escribiremos libros/ Si no quieren callar,/ vamos a hablar más alto (147).

Este poema pone en primer plano los territorios que las mujeres están «ocupando» para ser escuchadas. Los libros, los saraus y las batallas de poesía. Los saraus vienen funcionando, de hecho, como un espacio clave de articulación, valorización, legitimación y difusión de la palabra de las mujeres negras. Se trata de encuentros, al final del día (en la "noche de los proletarios", como diría Rancière 20), para declamar o leer poemas o textos propios en los bares localizados principalmente en las periferias o favelas de las grandes ciudades (Tennina 134). Los "saraus» hicieron que los espacios exclusivamente masculinos empezaran a ser frecuentados también por las mujeres, quienes poco a poco fueron tomando la palabra, acercándose al micrófono, primero, publicando libros autorales, y después, incluso, creando sus propios saraus exclusivamente femeninos. Al movimiento de saraus, le siguió el movimiento de "slams» o «batallas de poesía» que en términos generales está formado por mujeres. La propia Mel Duarte se define, además de como poeta, como "slammer» (integrante del Slam das Minas). Es en esos espacios en los que las mujeres se vuelven "revolucionarias de lo cotidiano" a través de la palabra y de la literatura, donde lo cotidiano no solamente es un espacio de rutina y opresión, sino también de creación y agencia. Por otro lado, es en esos espacios donde la palabra se vuelve un bien simbólico que permite la propia existencia, como dice Djamila Ribeiro, "o falar não se restringe ao ato de de emitir palabras, mas a poder existir" (64). 


\section{Consideraciones finales}

La literatura de autoría negra brasileña, desde su diversidad y complejidad, permite comprender ampliamente las operaciones propias del canon ligadas a una visión restringida y exclusiva de la literatura, vinculada directamente a ciertos privilegios estéticos y también sociales. El estudio de la autoría negra en relación con la literatura brasileña implica, en este sentido, una operación de revisión del canon y sus implicancias. En este artículo, me ocupé de analizar los impactos del perfil blancocéntrico de la literatura brasileña y los diálogos y las operaciones que desde la literatura de autoría negra se establecen ante estas maniobras. El análisis de estas producciones resulta clave para las futuras miradas críticas sobre la literatura brasileña y sus sensibilidades sobre Brasil, en función de tener, todavía, esperanzas de pensarlos desde una mirada democrática, diversa y plural.

\section{Referencias}

Abdala, Antonio C. y Tarsilinha do Amaral. Tarsila do Amaral. Percurso Afetivo. Rio de Janeiro: Ministério da Cultura do Brasil, 2012. Impreso.

Andrade, Oswald. Obras Completas. V. Ponta de lança. Rio de Janeiro: Civilização Brasileira, 1971. Impreso.

Arman, Neto. "18 poetas brasileiros que a curadoria de literatura do Instituto Moreira Salles deveria conhecer". Impressões de Maria. Web. 28 abr. 2019 <https://uww.impressoesdemaria.com.br/2019/04/18-poetas-brasileiros-que-curadoriade.html>

Assumpção, Carlos. Quilombo. Cartografía de la autoría negra brasileña. Trad. Lucía Tennina. Buenos Aires: Tinta Limón, 2019. 19-21. Impreso.

Barreto, Lima. Obras completas. São Paulo: Brasiliense, 1956. Impreso.

Bastide, Roger. A poesia Afro Brasileira. São Paulo: Martins Fontes, 1943. Impreso.

Bourdieu, Pierre. La dominación masculina. Trad. Joaquín Jordá. Barcelona: Anagrama, 2006. Impreso.

Buarque de Hollanda, Heloísa. "La literatura más allá de la marginalidad". Manual Práctico del odio. Trad. Lucía Tennina. Buenos Aires: Corregidor, 2012. 277-288. Impreso.

Brito, Carina. "Campanha resgata imagem de Machado de Assis como negro". Revista Galileu. Web. 
<https://revistagalileu.globo.com/Cultura/noticia/2019/05/campanha-resgata-imagemde-machado-de-assis-como-negro.html>

Castro Alves, Antônio F. "Navio Negreiro". Os escravos. Dominiopublico. Web. n. d. <http://www.dominiopublico.gov.br/pesquisa/DetalheObraForm.do?select_action=\&co_ obra $=16727>$

Cuti. Literatura negro brasileira. São Paulo: Selo Negro, 2010. Impreso.

Cuti. "Quebranto". Quilombo. Cartografía de la autoría negra brasileña. Trad. Lucía Tennina. Buenos Aires: Tinta Limón, 2019. 42-43. Impreso.

Crenshaw, Kimberlé. "Cartografiando los márgenes. Interseccionalidad, políticas identitarias, y violencia contra las mujeres de color". Intersecciones: cuerpos y sexualidades en la encrucijada. Barcelona: Ediciones Bellaterra, 2012. 87-122. Impreso.

Dalcastagnè, Regina. Representación y resistencia en la literatura brasileña contemporánea. Trad: Lucía Tennina. Buenos Aires: Biblos, 2015. Impreso.

De Almeida Pereira, Edimilson. "El grito". Quilombo. Cartografía de la autoría negra brasileña. Trad. Lucía Tennina. Buenos Aires: Tinta Limón, 2019. 82. Impreso.

De Assis Duarte, Eduardo. "Por um conceito de literatura afro-brasileira". Teoria Literária. Abordagens históricas e tendências contemporâneas. Maringá: Eduem, 2019. 367-383. Impreso.

De Jesus, Carolina Maria "Quarto de desechos". Quilombo. Cartografía de la autoría negra brasileña. Trad. Lucía Tennina. Buenos Aires: Tinta Limón, 2019. 16-18. Impreso.

Derrida, Jacques. Mal de archivo. Una impresión freudiana. Trad. Paco Vidarte. Madrid: Editorial Trotta, 1997. Impreso.

Dos Reis, M. Firmina. Ursula. Porto Alegre: Zouk, 2018. Impreso.

Duarte, Mel. "Nos quieren callar". Quilombo. Cartografía de la autoría negra brasileña. Trad. Lucía Tennina. Buenos Aires: Tinta Limón, 2019. 147. Impreso.

Evaristo, Conceição. "Gênero e Etnia: uma escre(vivência) de dupla face". Nossaescrivivencia. Web. Agos. $2020<$ http://nossaescrevivencia.blogspot.com/2012/08/genero-e-etniauma-escrevivencia-de.html>

Evaristo, Conceição. "Voces-mujeres". Quilombo. Cartografía de la autoría negra brasileña. Trad. Lucía Tennina. Buenos Aires: Tinta Limón, 2019. 29-30. Impreso.

Evensi. "Oficina irritada (poetas falam)". Evensi. Web. n. d. <https://www.evensi.com/oficinairritada-poetas-falam-instituto-moreira-salles/304641818> 
Fenske, Elfi K. "Carolina Maria de Jesus - a voz de quem não tem palavra". Templo cultural Delfos. Web. may. 2014 <http://mww.elfikurten.com.br/2014/05/carolina-maria-de-jesus.html> Foucault, Michel. La arqueología del saber. Trad. Aurelio Garzón. Buenos Aires: Siglo XXI, 2011. Impreso.

Jameson, Frederic. "Posmodernismo y sociedad de consumo". La posmodernidad. Trad. Jordi Fibla. Barcelona: Kairós, 1998. 165-186. Impreso.

Kilomba, Grada. Memórias da plantação. Episódios de racismo cotidiano. Rio de Janeiro: Cobogó, 2019. Impreso.

Lichterbeck, Philipp. "Rio ist ein Sehnsuchtort für hüftsteife Europäer". Tagesspiegel. Web 7 oct. $2013<$ <ttps://www.tagesspiegel.de/gesellschaft/paulo-lins-ueber-seinen-neuen-romanlins-ueber-samba-und-rhythmus-/8888592-2.html>

Magnani, Guilherme. Jóvens na metrópoli. Etnografias de circuitos de lazer, encontro e sociabilidade. São Paulo: Terceiro Nome, 2007. Impreso.

Marques, Eliane. "6". Quilombo. Cartografía de la autoría negra brasileña. Trad. Lucía Tennina. Buenos Aires: Tinta Limón, 2019. 93. Impreso.

Medeiros da Silva, Mario. "La fuerza de la literatura negra y de la literatura marginal periférica brasileñas". Quilombo. Cartografía de la autoría negra brasileña. Trad. Lucía Tennina. Buenos Aires: Tinta Limón, 2019. 275-290. Impreso.

Moretti, Franco. Lectura distante. Trad. Lilia Mosconi. Buenos Aires: FCE, 2015. Impreso.

Neiva, Leonardo. "Com rosto ainda desonhecido, primeira escritora negra do Brasil é redescoberta após décadas de anonimato". BBC News Brasil. Web. 25 jul. 2020 $<$ https://www.bbc.com/portuguese/geral-53411587>

Perpetua, Elzira D. "A construção do outro nas edições e traduções da obra de Carolina Maria de Jesus". Estudos de Literatura Brasileira Contemporânea. Ene. - Febr. 2019: 1-11. Digital.

Rama, Ángel. "Conversación en torno del testimonio". Casa de las Américas. 36. 1995. 122-123. Impreso.

Ramos, Cleidana. "CEF retira vídeo com Machado de Assis representado por branco". A tarde. Mundo afro. Web. 21 set. 2011 <http://mundoafro.atarde.uol.com.br/cef-retira-videocom-machado-de-assis-representado-porbranco/?doing_wp_cron=1597230646.2381050586700439453125>

Rancière, Jacques. La noche de los proletarios. Buenos Aires: Tinta Limón, 2010. Impreso.

Ribeiro, Djamila. O que é lugar de fala? Belo Horizonte: Letramento, 2017. Impreso. 
Rodríguez, María Fernanda. "O Brasil sem exotismos". O Estadão. Web. 5 jul. 2013. <https://cultura.estadao.com.br/blogs/babel/em-frankfurt-o-brasil-sem-exotismo/>

Sayers, Raymond. The negro in brazilian literature. New York: Hispanic Institute in the United States, 1956. Impreso.

Schwartz, Jorge. Las vanguardias latinoamericanas. Textos programáticos y críticos. Trad. Estela dos Santos. México D. F.: FCE, 2006. Impreso.

Souza Santos, Lívia N. "Poéticas da diferença: a representação de si na lírica afro-femenina". A cor das letras. 12. Ene. 2011: 105-124. Digital.

Tennina, Lucía. ¡Cuidado con los poetas! Literatura y periferia en la ciudad de São Paulo. Rosario: Beatriz Viterbo, 2018. Impreso.

Von Metz, Michaela. "140 Schattierungen von Braun". Süddeutsche Zeitung. Web. 4 agos. 2013 $<$ https://www.sueddeutsche.de/kultur/rassismus-in-brasilien-140-schattierungen-vonbraun-1.1737750>

Zumthor, Paul. Tradição e esquecimento. Trad. Jerusa Pires. São Paulo: HUCITEC, 1997. Impreso.

n. p. "Correio da Manhã (RJ) - 1901 a 1909" (documento número 2634). Hemeroteca digital de la Biblioteca Nacional Digital de Brasil. Web. n. d. <http://memoria.bn.br/pdf/089842/per089842_1908_02634.pdf 